\title{
Nutrition in health and disease: a Kuwaiti societal perspective representing the gulf cooperation council countries
}

\begin{abstract}
Kuwait is one 6 nations known as the Gulf Cooperation Council (GCC) countries that share many features in common - thus, conditions in Kuwait can be very similar to the rest of the countries in this region. While agriculture is limited in Kuwait and in most of these countries, their populations enjoy abundance of food. Nutrition-related diseases, such as: obesity, diabetes, hypertension, heart disease and anemia are prevalent in Kuwait. For example; overweight and obesity in children, adolescents and adults could be among the highest in the world. Steps towards prevention of such diseases would ensure public health and entail less cost for medical care and loss of productivity. The association between nutrition and health has long been established. Sound nutrition knowledge is the key to healthy dietary attitudes and practices, which leads to a healthy body and protects against several diseases. While the country has policies and programs to improve nutrition and food security, nutrition education efforts can be the first step towards improved knowledge by the public and could lead to better food choices and, consequently, balanced and healthy diet. Following recommended dietary guidelines along with emphasis on regular physical activity are keys to preservation of health and towards combating the development of nutritionrelated diseases. Many entities in Kuwait should work cooperatively towards enhancing nutrition education and awareness among all segments of society. It is recommended that adequate resources be allocated for as many nutrition education programs as possible and for making sport and physical activity facilities abundantly available. Such measures would prove to be a successful investment strategy for the overall well-being of society. As the rest of GCC countries share many features with Kuwait, dietary and lifestyle recommendations for Kuwait can be applicable to all GCC countries.
\end{abstract}

Keywords: disease, education, health, Kuwait, nutrition, society
Volume 2 Issue 5 - 2015

\section{Farouk El-Sabban}

Department of Food Science and Nutrition, Kuwait University, Kuwait

\author{
Correspondence: Farouk El-Sabban, Department of Food \\ Science and Nutrition, College of Life Sciences, Kuwait \\ University, P.O. Box 5969 - Safat, Kuwait City, Kuwait, Tel \\ +9652463308I, Fax +965225I3929, \\ Email farouk.elsabban@ku.edu.kw
}

Received: July 26, 2015 | Published: September 18, 2015
Abbreviations: GCC, gulf cooperation council; BMI, body mass index; RBC, red blood cells

\section{Introduction}

Human survival and health are mainly influenced by three main factors, which are: genetics, environment and nutrition. There are some diseases that have genetic basis, thus the genetic makeup of an individual can determine his/her susceptibility to such diseases. In contrast to the other two influencing factors, genetic makeup cannot be changed. Some environmental aspects can be individuallycontrolled, such as at home and office - while others cannot, such as climate, local community and global environments. The association between nutrition and health has been established. Sound nutrition knowledge is the key to healthy dietary attitudes and practices, which leads to a healthy body and protects against several diseases. Healthy nutrition can be followed to preserve the individual's general health and sound dietary habits can be learned and practiced. Thus, awareness of the basis of good nutrition by all individuals of society would be beneficial to the society at large.

The Gulf Cooperation Council (GCC) countries are six and are located in the Arabian Peninsula or connected to it. The GCC was formed in 1981 that includes: Bahrain, Kuwait, Oman, Qatar, Saudi Arabia and United Arab Emirates (Figure 1). Combined, all these countries have a population of nearly 50million- the largest of which is Saudi Arabia (30million) and the smallest is of Bahrain (1.6million).

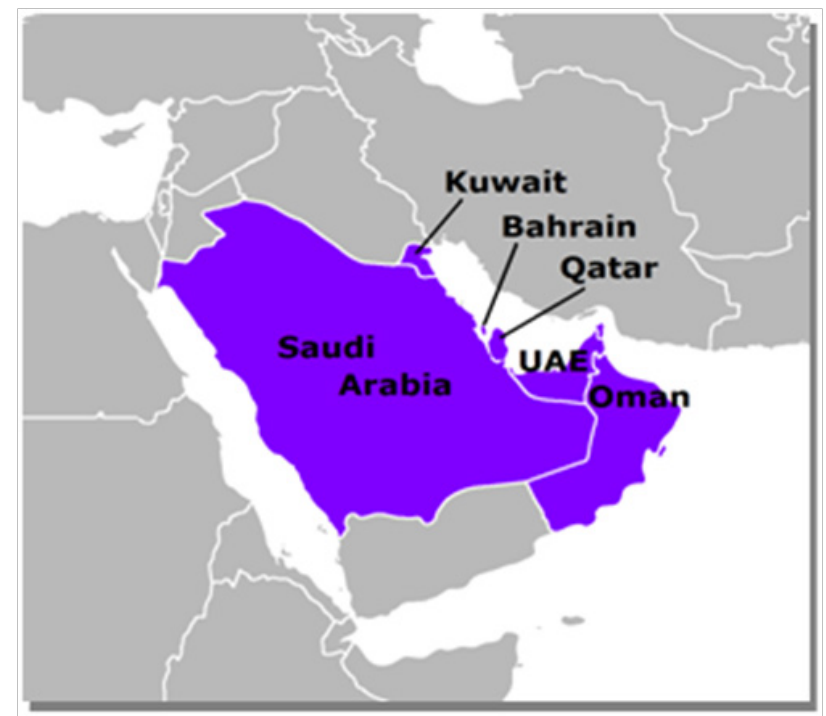

Figure I Map of the Arabian Gulf countries.

Source Google Maps. 
The discovery of oil in these countries in the last century has led them to enjoy the highest per capita income among countries of the world, with many socio-economic changes taking place. With the presence of wealth, many infrastructural and developmental projects were and are being planned. This increased the demand for manpower required, thus many migrant workers from many countries are present in these countries. While the total population in these countries is about 50million, the ratio of citizens to non-citizens is variable. Available statistics show that percentages of non-citizens range from $32 \%$ in Saudi Arabia to $88 \%$ in the United Arab Emirates. The presence of different ethnic groups in GCC countries makes them enjoy a state of cultural diversity.

Kuwait is a small oil rich urban state, where agriculture is limited, thus most of the food commodities for human consumption other than aquatic are imported. ${ }^{2}$ The population of Kuwait is approximately 3.6million - where $98.3 \%$ of population lives in urban areas: $98.3 \%$ and the population proportion between ages 30 and 70 years is $45.8 \%{ }^{3}$ The country enjoys a state of abundance of food, most of which is imported. With abundance of food in Kuwait, per capita daily caloric consumption was shown to increase from 2,600 to $3.100 \mathrm{Kcal} .^{4}$ Nutrition-related diseases such as diabetes, obesity, high blood pressure, heart disease, and anemia are currently the most serious health problems in Kuwait. On average, nearly $20 \%$ of the population suffers from hypertension and $42 \%$ from obesity. ${ }^{3}$ A recent report indicated that heart diseases are the primary cause of death in Kuwait, representing more than 40 percent of the total deaths annually. ${ }^{5}$ The probability of dying among ages between 30 and 70years from the 4 main non-communicable diseases (cardiovascular diseases, cancer, diabetes, and chronic respiratory diseases) is about $12 \%{ }^{3}$

The need to curb and/or eliminate such prevalent diseases is urgent. While the country has policies and programs to improve nutrition and food security, ${ }^{2}$ nutrition education efforts can be the first step towards improved knowledge by the public and would lead to better food choices and, consequently, balanced and healthy diet. Information on the level of nutrition knowledge among segments of society in Kuwait is lacking. Assessing nutrition awareness and knowledge is a valuable tool to identify deficient areas of information and, thus, would aid in devising effective nutrition education approaches and programs. Nutrition education and awareness are measures for prevention of diseases and would ensure preservation of health. The objective of this report is to briefly explore prevalent nutrition-related diseases, their consequences, and the basis of good nutrition. The need for formation of a national nutrition awareness and education task force, with proactive approaches towards different segments of society, is being suggested herein.

\section{Prevalent nutrition-related diseases}

Kuwait went into a transition towards affluence because of the wealth generated from the discovery of oil. Many of modern days facilities and means for comfort are abundantly available. Food consumption patterns changed over the past four decades and diet in Kuwait and the rest of the Arabian Gulf countries turned towards being energy-dense. ${ }^{6,7}$ With increased food consumption and with insufficient physical activities, many nutrition-related diseases, especially coronary heart disease, became most prevalent in these countries. $^{7}$ While there are many statistics about aspects of health in Kuwait, ${ }^{8}$ a brief account of major nutrition-related diseases is shown below.

\section{Overweight and obesity}

There is an average and/or normal weight for individuals, which relates to height and body frame size. Excess body weight, and consequently change in body shape, is mainly due to accumulation of fat. The measure for this is known as the body mass index (BMI), which takes into account body weight and height (body weight/height 2). Normal weight has a BMI range of 18.5-24.9. Overweight and obesity have the ranges of 25.0-29.9 and above 30.0, respectively. Overweight and obesity among adults in Kuwait could be one of the highest in the world and childhood obesity is prevalent and rising. ${ }^{9-11}$ Prevalence of overweight and obesity in adolescents averaged 30 and $15 \%$, respectively. ${ }^{12}$ Obesity is considered as a major risk factor for other serious diseases, such as diabetes, hypertension and other cardiovascular diseases. ${ }^{13}$ Healthy nutrition, both quality and quantity, and leading an active lifestyle would greatly alleviate this major problem. $^{14}$

\section{Diabetes mellitus}

Is a disease characterized by high level of blood sugar (glucose) in the blood and its presence in urine. It results for lack of secretion of insulin from the pancreas and or lack of sensitivity to present insulin in the body. ${ }^{13}$ Prevalence of diabetes in Kuwait is among the highest in the world, estimated to be about $20 \%$. Diabetes is a disease with many serious consequences on health and life of the individual. Special dietary measures help in alleviating the severity of diabetes, along with the use of proper medications.

\section{Cardiovascular diseases}

These are diseases that involve the heart and the blood vessels. Prevalent diseases of this category are:

Atherosclerosis: Is a chronic disease in which arteries (blood vessels that deliver blood to body organs) become narrow and do not allow blood to flow freely. The narrowing of these vessels is mainly due to accumulation of cholesterol (a waxy substance) and other substances that form solid masses attached to the inside of an artery (plaque). Consequences of this condition can be fatal, as it may lead to a heart attack or a stroke. ${ }^{13}$ People with a family history of high blood cholesterol level ought to be particularly careful and observe dietary habits that would restrict the intake of foods that are high in fats and cholesterol. ${ }^{14}$

Hypertension: This means repeated blood pressure readings of $140 / 90 \mathrm{mmHg}$ or higher. This disease has serious consequences, as blood vessels can burst and blood leaves the vessels (hemorrhage) and could also be a cause for formation of blood clots that can be fatal. ${ }^{13}$ Special diets that contain less sodium, along with a balanced diet, can be effective in reducing the adverse effects of this condition.

Heart attack: This results from narrowed heart arteries and with the formation of blood clots that block the major arteries of the heart. The heart cannot operate when its blood supply is blocked, as there would not be any oxygen or nutrients delivered. If the person is not revived with a few minutes, the result would be death. The probability of having a heart attack can be dramatically reduced by following health dietary habits and by leading an active lifestyle to maintain normal body weight. ${ }^{14}$

Stroke: This results from formation of a blood clot in arteries in the brain or in major arteries of the neck leading to the brain. The 
nerve cells of the brain are very sensitive to the presence of oxygen and glucose that are delivered by blood. Brain cell damage can be permanent and may lead to death if proper treatment is not initiated. Among the major factors that reduce the risk of a having a stroke are to follow sound nutrition and to be physically active on a daily basis. ${ }^{14}$

Anemia: Means any deficiency in red blood cells (RBC). This can be related to low RBC count or abnormality in RBC shape, size or components. ${ }^{13}$ Among the most prevalent conditions of this category in Kuwait is iron-deficient blood. This is typically a condition that most women in their child-bearing years suffer from as well as their children. ${ }^{15}$ Iron deficiency does not allow blood to carry enough oxygen, which leads to delivery of less oxygen to bodily tissues. Those who suffer from iron-deficiency anemia lack energy and fatigue easily; thus they cannot be that productive. With the proper diet, and with iron supplementation, this problem can be alleviated or eliminated.

\section{Basics of healthy nutrition}

In order to be aware of the importance of nutrition in preserving health and in preventing nutrition-related diseases, a brief exploration of the basics of good nutrition (also known as healthy nutrition) is hereby illustrated. Basic understanding of human nutrition at different stages of development is also briefly included. Nutrient requirements that are recommended for maintenance of health are based on data that were generated from many scientific studies. Also, it should be emphasized that adequate and well balanced nutrition ought to be observed in all phases of human life explored below.

\section{Food groups}

There are four main food groups, which are: 1) grains and cereals, 2) milk and dairy products, 3) meats and meat products, and 4) fruits and vegetables. While all these groups contain chemical substances that the body needs (nutrients), each provides more of certain nutrients. Grains and cereals contain carbohydrates (like starch and sugars), that the body needs for energy. Milk and dairy products provide the body with calcium, carbohydrates (the sugar lactose) and protein. Meats and meat products provide most of the protein that the body needs for growth and repair of tissue. The fruits and vegetables group provides the body with water, minerals and vitamins (which are needed for many biological functions in the body).

\section{Classes of nutrients}

There are six classes of nutrients (chemical substances) that the body needs for normal growth and functions. These are: carbohydrates, proteins, lipids, minerals, vitamins and water. Carbohydrates are needed for generation of energy, proteins are to provide the nitrogen that is needed for growth and repair of damaged tissues, lipids (fats and oils) are needed for energy production, minerals are needed for many biological functions (e.g., being components of bones, carry oxygen in blood), vitamins can help in fighting diseases and are involved in many biological processes involved in body metabolism (building up and destroying substances and structures). Water is a very special class of nutrients, as it constitutes about $2 / 3$ of total adult body and serves many vital functions in the body.

\section{Healthy nutrition}

This expression means that each individual consumes adequate amounts of all food groups, i.e., to observe balanced nutrition. This way, there would be assurance that such a diet would provide the body with the needed nutrients on a daily basis. There are means to guide the public about healthy nutrition, most known and practiced is the food guide pyramid (Figure 2) that was devised by the United States Department of Agriculture in 2005. ${ }^{16}$

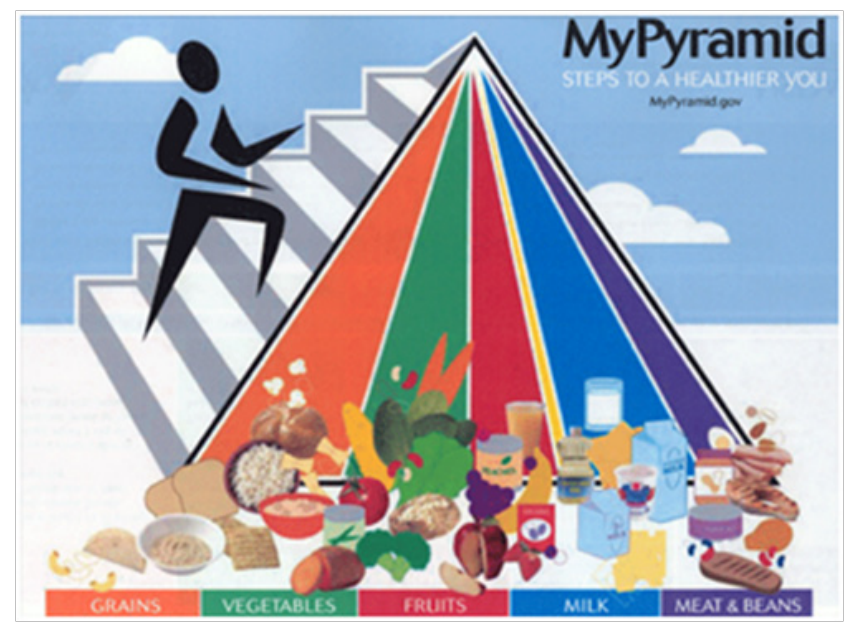

Figure 2 The food guide pyramid.

Source United States Department of Agriculture. ${ }^{16}$

\section{Nutrition of infants}

Based on the recommendations of the World Health Organization of the United Nations (WHO-UN), a new born baby should be breast-fed for the first 6months of his/her life. ${ }^{17}$ Mother's milk is the most perfect and natural food for babies at this age, thus should be encouraged and promoted. Introduction of semi-solid foods and those that are easy to digest begin after the first six months of age.

\section{Nutrition of children}

This phase of development is characterized by fast growth for both boys and girls. Up until the next phase (adolescence), there are no much differences in the nutrient requirements between both genders. It is natural for children to be active, thus their energy requirements increase. Sound nutrition should be followed for children to achieve normal weight and height. Food guides have been devised for proper nutrition of young children, such as that is shown in Figure $3 .{ }^{18}$ Caution should be observed so that children would not eat foods that are high in fat such as those that are fried and those that contain readily available sugar such as candy and chocolates.

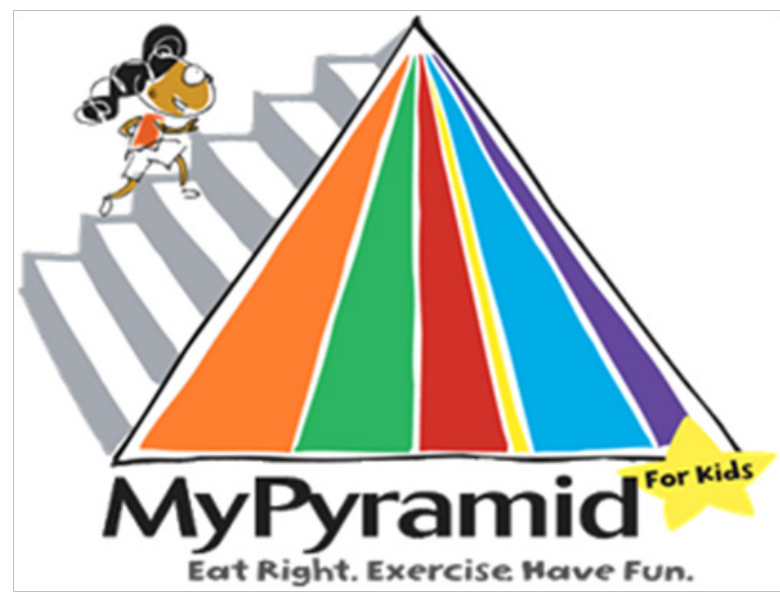

Figure 3 Food guide pyramid for kids.

Source Nutrition Exploration. ${ }^{18}$ 


\section{Nutrition of adolescents}

Growth continues in this phase and, consequently, nutrient requirements increase. Additionally, adolescents are physically active in general, thus, their energy requirements are expected to increase. Nutrient requirements begin to be higher for boys than for girls at this stage of development, as they become more masculine. Girls at this stage begin to be aware of their figure and become influenced by the mass media that glorifies thinness, a matter that can be the cause of much anxiety and may lead to some psychological problems.

\section{Nutrition of adults}

Nutrition of males and non-pregnant females: During the adult phase, there are differences in nutrient requirements between males and non-pregnant females. Adult males generally have 10\% higher requirements of protein and energy than females of the same age category.

Nutrition of the pregnant: The pregnancy period is about 9months, divided into 3 stages (trimesters). Requirements for nutrients and energy increase gradually, above those of non-pregnant females, to satisfy the growth of the fetus as the pregnancy progresses. The last three months of the pregnancy is characterized by fast growth of the fetus to be fully developed, thus nutrient requirements increase dramatically-especially for certain nutrients such as iron, calcium, folic acid, protein and also for energy.

Nutrition of the lactating mother: It is natural that the mother would nurse her baby immediately after birth. Mother's milk contains sufficient nutrients for nutrition of the new born infant. Thus, nutrient requirements of the lactating women are higher than those who are not pregnant - especially for protein and energy.

Nutrition of the elderly: Attention to the nutrition of the elderly started about 35years ago. With the advances in medical services and development of new medications, life span of individuals increased and the percent of the elderly population in society became sizable. Nutrition of the elderly presents a challenge in any society- as there many influencing physical, pathological, psychological and social factors involved. Generally, nutrient requirements for the elderly are less than for adults, while taking into account many special nutritional considerations for their well-being. ${ }^{19}$

It should be noted that following a healthy-type nutritional pattern is not sufficient for having a healthy existence. Thus, the term "healthy lifestyle" was coined. Emphasis for having a healthy lifestyle entails the following of a healthy dietary pattern and being engaged in a regular physical activity program. Individuals who are physically active are able to maintain their normal body weight - thus avoiding one serious risk factor for disease (overweight and obesity). Proper cardiovascular conditioning and proper level of muscle toning are major benefits of regular physical activity programs.

\section{Consequences of disease in society}

Development and progress of society is dependent to a large extent on the productivity of its population. Healthy citizens are expected to be able to achieve and be productive. General health is defined by WHO-UN that humans would be free of disease and are in good psychological and mental states. Any society strives to have its citizens enjoy general health condition, for which a significant percent of its financial resources are allocated. The burden of having diseases in society entails increased allocations and resources spent on medical care and services. Diseased persons are likely to be less productive than their healthy counterparts and would be absent from their work place if their illnesses are serious. Loss of productivity and work hours constitute a loss to society and drainage of its finances and resources. Nearly 10years ago, it was estimated that obesity alone costs Kuwait nearly 2.8billion US Dollars annually. ${ }^{10}$ Costs of care for other diseases would also be of a high magnitude. Following sound nutrition by all segments of society and by leading an active lifestyle would prove beneficial for the society at large. Thus, enhancement of the public's awareness of good nutrition basics and dietary practices is an important key to having a healthy population.

\section{Suggestions for nutrition awareness and education}

Enhancing knowledge about nutrients, their significance for the body, and healthy nutrition for all segments of society is a key measure to ensure having a healthy and consequently a productive population. Thus, it is proposed that there would be a national nutrition awareness campaign in which several entities involved have to coordinate and cooperate. The formation of a national nutrition awareness and education task force is hereby suggested. Such a task force would develop proactive approached to educate the public about nutrition and its significance in relation to general health.

While it is ideal that each person would seek information about nutrition as a way of caring for one's health, the responsibility for nutrition awareness and education in society would be on the Ministry of Health, private clinics and hospitals, Ministry of Education, colleges and universities, social associations and sporting and religious groups. There must be a clear strategy for the nutrition awareness and education campaign and its objectives should be clear and measurable, for making a judgment on its effectiveness and success. Because of the diversity in targeted segments (sub-populations), involved entities can vary. For example, a program that promotes breast feeding of infants would mainly involve, among others, the Ministry of Health, private hospitals, social and religious entities. Programs for school children would involve the child parents (who are hoped to be nutritionally aware), the Ministry of Education (teachers), and the mass media (newspapers, magazines, radio and television). Diverse educational means and approaches can be implemented in this campaign, such as: different types of publications (broachers, booklets, leaflets...etc.), courses and workshops, general and specific events, as well as simple messages to the public in the mass media (especially television).

While the main objective is to educate the general public about nutrition, there are certain segments of society that require special attention. One of these segments is that of children and adolescents. It is known that healthy dietary habits established in childhood may also be carried over into adulthood. Studies have shown that nutrition knowledge among children and adolescents is insufficient. ${ }^{20,21}$ Therefore, it is recommend that parents, teachers and other influential adults guide children and adolescents in developing healthful eating patterns..$^{22}$ Also, the area of nutrition of the elderly should be given adequate attention in Kuwait and nutrition of the disabled ought not to be neglected.

\section{Conclusion}

The level of nutrition awareness and education in Kuwait and the rest of the GCC countries need to be elevated as a critical measure to protect against prevalent nutrition-related diseases. The formation 
of a national nutrition awareness and education task force in each of the GCC countries is proposed. Such a task force would include all entities involved. A clear and quantifiable strategy ought to be drawn and implemented. Close cooperation and collaboration among Arabian Gulf countries are crucial in the success of such strategy. Assessing the level of nutrition knowledge and in relation to general health can be a first step towards drawing specific education programs for different segments of society. Enhancing nutrition knowledge and increasing facilities for physical activity for the public would most certainly impact the general health and well-being of the society at large. For implementing a successful campaign, collective collaborative efforts of many segments of society ought to be put into practice. Also, for an overall benefit to populations in the GCC countries and those of others in the region, cooperation and sharing of experiences among these countries should be encouraged and promoted.

\section{Acknowledgements}

None.

\section{Conflict of interest}

Author declares that there is no conflict of interest.

\section{References}

1. El-Sabban F. Status of food and nutrition in the Arabian Gulf countries. International Journal of Agriculture Science and Food Technology. Peerstechz Publishers; 2015;1(1):101.

2. Kuwait Nutrition Profile. Nutrition and Consumer Protection Division. FAO; 2006.

3. WHO International. Kuwait; 2015.

4. FAO. Food Balance Sheet. Rome; 2000.

5. Kuwait Times. Heart diseases main cause of death in Kuwait. 2015.

6. Al-Hooti S, Himmo NS, Al-Amiri H, et al. Food consumption pattern for the population of the State of Kuwait based on food balanced sheets. Ecology of Food and Nutrition. 2002;41(6):501-514.

7. Musaiger AO. Diet and prevention of coronary heart disease in the Arab Middle East countries. 2002. Medical Principles and Practices. 2002;11(Suppl 2):9-16.
8. Kuwaiti Health Statistics. 2015.

9. Ng SW, Zaghloul S, Ali AI, et al. The prevalence and trends of overweight, obesity and nutrition-related non-communicable diseases in the Arabian Gulf States. Obes Rev. 2010;12(1):1-13.

10. Rotimi K. Kuwait has the highest obesity level in the world: A policy proposal to reduce prevalence. The 133rd Annual Meeting \& Exposition. Philadelphia: American Public Health Association; 2005.

11. Shady I, Lotfy H. Prevalence of obesity among adolescents (10-14years) in Kuwait. Asia-Pacific Journal of Public Health. 2009;21(2):153-159.

12. Al-Isa AN. Body mass index, overweight and obesity among Kuwaiti middle school adolescents aged 10-14years. Eur J Clin Nutr. 2004;58(9):1273-1277.

13. Shier D, Butler J, Lewis R. Hole's Essentials of Human Anatomy and Physiology. 9th ed. New York: McGraw-Hill; 2006.

14. Whitney EN, Rolfes SR, Pinna K. Understanding Normal and Clinical Nutrition. 9th ed. Belmont, CA: Wadsworth Publishing; 2002.

15. Al-Haifi A, Huffman FG. Feeding practices influence weight and hemoglobin status in Kuwaiti infants. Ecology of Food and Nutrition. 2004;43(1):41-59.

16. United States Department of Agriculture.

17. Gibney MJ, Margetts BM, Kearney JM, et al. Public Health Nutrition. 1st ed. Oxford: Blackwell Science; 2004.

18. Nutrition Explorations. Kids Nutrition Pyramid. 2010.

19. El-Sabban F. Considerations in the nutrition of the elderly population. The 2nd Middle East Congress on Age, Ageing and Alzheimer. Tripoli, Lebanon; 2009:4-6.

20. Niciforovic-Surkovic, Kvrgic OS, Ac-Nikolic E. Knowledge of nutrition and nutritional behavior of schoolchildren and their parents in Vojvodina. Med Pregl. 2002;55(11-12):465-469.

21. El-Sabban F, Badr HE. Assessment of nutrition knowledge and other aspects among first-year Kuwait University students. Ecol Food Nutr. 2011;50(2):181-195.

22. Blaylock JR, Variyam JN, Lin BH. Maternal Nutrition Knowledge and Children's Diet Quality and Nutrient Intakes. Food and Rural Economics Division. Economic Research Service, U.S. Department of Agriculture. Food Assistance and Nutrition Research Report No. 1. 1999. 